\title{
AS DIVERGÊNCIAS ENTRE MUNICÍPIOS E CONTRIBUINTES NA ESTIPULAÇÃO DA BASE DE CÁLCULO DO ITBI EM IMÓVEIS ADQUIRIDOS POR MEIO DE LEILÕES JUDICIAIS E EXTRAJUDICIAIS
}

Klaus Almeida Struecker ${ }^{1}$

\section{RESUMO}

O foco do presente trabalho é a conjuntura tributária, especificamente quanto à demonstração de que a base de cálculo do ITBI é o valor alcançado em leilão na compra e venda de um imóvel adquirido por meio de hasta pública. O ITBI é o Imposto de Transmissão de Bens Imóveis, um tributo municipal aplicado sobre transferências imobiliárias. A responsabilidade do pagamento do tributo costuma obedecer às leis municipais. No caso de bem adquirido em hasta pública, verifica-se que o ITBI deve ser calculado sobre o preço pago pelo arrematante e não sobre o valor de mercado.

Palavras-chave: ITBI; imóveis; valor venal; leilão; tributo.

\section{THE DIFFERENCES BETWEEN MUNICIPALITIES AND TAXPAYERS IN THE ESTABLISHMENT OF THE ITBI CALCULATION BASIS IN PROPERTIES PURCHASED THROUGH JUDICIAL AND OUT-OF-COURT AUCTION}

\begin{abstract}
The focus of this paper is the tax situation, specifically regarding the demonstration that the ITBI calculation base is the value reached at auction in the purchase and sale of a property acquired through public auction. ITBI is the Real Estate Transfer Tax, a municipal tax imposed on real estate transfers. Responsibility for paying the tax tends to obey municipal laws. In the case of property acquired at public auction, it appears that the ITBI should be calculated on the price paid by the bidder and not on the market value.
\end{abstract}

Keywords: ITBI; properties; venal value; auction; tribute.

\section{INTRODUÇÃO}

O objetivo do trabalho em questão é a análise no âmbito tributário, particularmente quanto à demonstração de que a base de cálculo do ITBI, com fulcro no Código Tributário Nacional (CTN), é o valor alcançado em leilão na compra e venda de um determinado imóvel adquirido por meio de hasta pública.

Nos negócios de compra e venda de bens imóveis, particularmente tratando de arrematação de imóveis de leilões judiciais e extrajudiciais, o arrematante (comprador) deve

\footnotetext{
${ }^{1}$ Bacharel em Direito do Estado pela Universidade Federal do Paraná (UFPR). Pós-Graduado em Direito Corporativo e Compliance pela Escola Paulista de Direito (EPD). Pós-Graduado em Direito Tributário pelo Instituto Brasileiro de Estudos Tributários (IBET-SP). Metrando em Direito Empresarial e Cidadania na Unicuritiba. Advogado.
} 
arcar com os custos do Imposto de Transmissão de Bens Imóveis (ITBI) ao município em que o bem se localiza. Assim, a simples compra de bens imóveis é situação que enseja a cobrança do ITBI, que deve ser pago pelos compradores.

Com efeito, na aquisição de imóveis através dos leilões, é comum que o valor de compra de um certo imóvel fique abaixo do seu real valor de mercado, em razão da maneira como os leilões são estruturados, organizados e executados. Deste modo, a cobrança do ITBI sobre o valor assinalado pelas prefeituras acaba resultando no pagamento de um tributo maior do que o calculado com base no preço pago pelo comprador em praça pública.

Nesta situação, algumas prefeituras já adotam o valor do arremate como base de cálculo para a devida e regular cobrança do ITBI. Além disso, o judiciário brasileiro tem seguido o entendimento de que a base de cálculo do ITBI deve ser o valor alcançado em hasta pública, e não o valor estipulado de forma singular e isolada pelas prefeituras.

A Administração Pública pode estabelecer o valor da base de cálculo do ITBI, desde que instaure o devido e regular processo administrativo para isso, com contraditório e ampla defesa, de acordo com o art. 148 do CTN (Lei $\mathrm{n}^{\circ}$ 5.172, 1966). O contribuinte, por sua vez, possui o direito irrenunciável de conhecer previamente a base de cálculo incidente sobre o ITBI, sem que seja surpreendido durante o mesmo exercício fiscal pelo arbitramento unilateral da autoridade fazendária.

Assim, os leilões se tratam de uma alternativa para a aquisição de imóveis a um preço abaixo do mercado, seja para a compra e venda de imóveis como forma de investimento, seja para interesses pessoais de moradia ou aluguel.

\section{DEFINIÇÕES E OBJETIVOS}

A investigação acadêmica ora proposta será pautada pelo método dedutivo, a ser empreendido a partir de uma revisão bibliográfica multidisciplinar de livros e artigos científicos, tendo natureza essencialmente teórica, centrada na análise doutrinária e, no que couber, também legislativa do tema.

Proceder-se-á a um estudo que compreenda as principais obras jurídicas sobre o tema e que enfrentem devidamente a complexidade do objeto de estudo em questão. Com este método, será possível, num primeiro momento, revelar-se conceitos teóricos, tanto jurídicos quanto econômicos, pertinentes e necessários ao entendimento do tema.

O ITBI tem sua hipótese de incidência a transmissão de propriedade imobiliária 
inter vivos por ato oneroso, ou seja, recai apenas sobre a transferência de bem imóvel. $\mathrm{O}$ legislador municipal, por sua vez, está impedido de instituir o imposto em questão relativamente a algo que não esteja inserido na noção de "bem imóvel”, sob pena de afronta à Constituição (CARVALHO, 2013, p. 356).

A justificativa deste trabalho se explica porque, na prática, a forma de cobrança do ITBI tem sido objeto de conflitos administrativos e judiciais, opondo contribuintes e municípios. Somado a isso, importante avaliar a enorme relevância econômica deste imposto, pois são diversos os negócios jurídicos de transmissão de propriedade imobiliária sobre os quais incide. A existência de embates constantes sobre sua base de cálculo demonstra a importância da questão nas discussões práticas e teóricas.

A base de cálculo para a correta mensuração do ITBI a ser pago será o valor venal do imóvel ou o valor da compra e venda quando este for maior que os valores de referência da prefeitura. Entretanto, o entendimento adequado é que a base de cálculo deve se sustentar no valor que o bem alcançou no lance vencedor em praça pública.

A legislação pátria, por sua vez, estipula que o recolhimento do ITBI deve acontecer a partir da assinatura do auto de arrematação, o que pode fazer com que o arrematante recolha um valor indevido, visto que o não recolhimento dentro do prazo previsto na lei acarretará multa e juros.

Assim, o pagamento do ITBI deve ocorrer apenas no ato do registro da carta de arrematação, e não na data de ocorrência do leilão. Este é o entendimento já manifestado em decisões pelos Tribunais Superiores, que reconhecem a ilegalidade adotada pelos municípios na tributação desta maneira de compra de imóveis, tanto na base de cálculo adotada quanto na data estipulada para o recolhimento do imposto.

Diante deste quadro, é possível afastar não só a exigência da quantia paga a maior a título de ITBI, mas também a incidência de multa e juros, ou ainda recuperar possíveis pagamentos a maior nos últimos 5 (cinco) anos, por meio da propositura da adequada peça judicial. Portanto, no caso de bem adquirido em praça pública, o ITBI deve ser calculado sobre o preço pago pelo arrematante.

\section{A BASE LEGAL DO ITBI E SEUS FUNDAMENTOS}

De acordo com Coêlho (2015, p. 341): 
O fato jurígeno do ITBI se dá pela transmissão jurídica da propriedade, que pode ocorrer pela transcrição no registro de imóveis ou pelas outras formas previstas em lei. Esses institutos jurídicos corroboram a incidência tributária do ITBI.

Com supedâneo no art. 156, I, da Constituição Federal (CF), os municípios podem legislar (BRASIL, 1988):

sobre a transmissão inter vivos, a qualquer título, por ato oneroso, de bens imóveis, por natureza ou acessão física, e de direitos reais sobre imóveis, exceto os de garantia, bem como a cessão de direitos à sua aquisição.

Na visão de Harada (2000, p. 25), “o Senado Federal não mais interfere na fixação de alíquota máxima, como acontecia no regime constitucional antecedente. O município é livre para dosar a carga tributária”.

Segundo o art. 145, 149-A e 156 da Constituição Federal (BRASIL, 1988), as fontes próprias dos municípios são aquelas que a Constituição Federal atribuiu como de competência municipal: impostos (IPTU, ITBI e ISS); taxas; contribuições de melhoria e contribuição para custeio do serviço de iluminação pública.

Neste diploma legal está prevista imunidade específica ao imposto quando a propriedade dos bens e direitos forem incorporados ao patrimônio de pessoa jurídica em realização de capital, ou no caso da transmissão de bens ou direitos, seja decorrente de fusão, incorporação, cisão ou extinção de pessoa jurídica. Estão excluídos desta imunidade os casos em que o exercício predominante do contribuinte for a compra e venda desses bens ou direitos, locação de bens imóveis ou arrendamento mercantil.

Por outro lado, segundo o art. 38 do CTN (Lei n ${ }^{\circ} 5.172$, 1966), para o cálculo do imposto de ITBI deve ser utilizado o valor venal do imóvel. O valor venal do imóvel pode ser compreendido como uma estimativa realizada pelo Poder Público do valor de mercado que determinado bem atingiria com uma venda. Entretanto, em se tratando de alienação de bem imóvel em hasta pública (leilão judicial e extrajudicial), a base de cálculo do ITBI corresponde ao valor da quantia atingida no ato, ou seja, o valor da arrematação do imóvel em leilão.

A base de cálculo do ITBI é o valor venal dos bens ou direitos transmitidos, assim compreendido o valor pelo qual o bem ou direito seria negociado em condições normais de mercado para compra e venda à vista. $\mathrm{O}$ fato gerador do imposto é a transmissão onerosa de bens imóveis entre vivos. Esta delimitação do fato gerador diferencia o ITBI do ITCMD, 
cuja incidência é sobre a transmissão de bens causa mortis ou por doação, ou seja, transmissões gratuitas da propriedade.

Por outro lado, compete exclusivamente à lei complementar a determinação dos fatos geradores, bases de cálculo e contribuintes dos impostos. Neste sentido, tem-se que a lei com feição de complementar sobre as normas gerais de direito tributário, ora em vigor, é o Código Tributário Nacional, disposto na Lei Federal n 5.172/1966, no que não contrariar a CF, em seu art. 146 (BRASIL, 1988).

Nesta temática, com base no art. 110 do CTN (Lei $n^{\circ} 5.172,1966$ ), para o município instituir validamente esse imposto há que recorrer aos conceitos de direito civil a respeito de transmissão de bem imóvel, de direitos reais de garantia (hipoteca, penhor e anticrese), visto que esses conceitos dados pelo direito comum são vinculantes ao direito tributário.

É essencial que na definição do fato gerador do ITBI integre o conceito de transmissão de bem imóvel, tal qual definida no direito comum. Ademais, a transmissão da propriedade imobiliária apenas se concretiza através do registro efetivo do título translativo (escritura de compra e venda, de dação em pagamento, etc.) no Registro de Imóveis competente.

De acordo com Harada (2019, p. 1):

Interessante notar que em relação à arrematação de bem imóvel em hasta pública, cuja aquisição se dá igualmente sem a figura do transmitente, a jurisprudência de nossos tribunais tem exigido o pagamento prévio do ITBI, como condição para expedição do título judicial que servirá de base para a transcrição imobiliária no Registro de Imóveis competente. É, na verdade, um grande equívoco.

Ora, nos leilões não há transmitente, pois o bem é expropriado do devedor para o devido pagamento do credor. Ainda, o juiz que decide pela expedição da carta de arrematação não viabiliza o ato de transferência da propriedade que não é dele.

O ITBI incide sobre o valor da transação imobiliária ou sobre o valor venal de referência, o que for maior. Levando em consideração que o mercado imobiliário é variável e os preços dos imóveis se alteram constantemente, o valor da transação acaba sendo muitas vezes inferior àquele firmado como sendo valor de referência para fins de custeio do ITBI.

Deste modo, tornou-se comum, numa compra e venda, que o comprador tenha que recolher o ITBI sobre uma base de cálculo que não faça referência ao preço efetivamente pago em hasta pública, tornando a operação desvantajosa para aquele que arremata em 
leilões.

\section{LEILÕES JUDICIAIS E EXTRAJUDICIAIS}

Na definição legal da Lei de Licitações, leilão é a modalidade de licitação entre quaisquer interessados para a venda de bens inservíveis para a Administração. Estes bens podem ser produtos legalmente apreendidos ou penhorados, segundo o art. 22 da Lei $n^{\circ}$ 8.666/93 (BRASIL, 1993).

Encerrada a licitação, deve-se lavrar o auto de arrematação imediatamente para documentar o que nela se tenha passado. Caso tenha havido lance vencedor, válido e eficaz, o arrematante pode desistir até que esse auto seja lavrado. Todavia, assinado o auto, a arrematação considera-se perfeita, acabada e irretratável, e não será desfeita (PASSOS, 2015, p. 105).

O leilão judicial é a venda de bens apreendidos ou penhorados dentro de um determinado processo judicial. Desta maneira, podem ser colocados à venda: veículos, imóveis, máquinas ou qualquer outro ativo que permita o pagamento de uma dívida ou ressarcimento de um prejuízo causado. Nos leilões, há disputa entre os interessados no bem que está sendo ofertado em praça pública.

O leilão judicial é uma forma de venda pública, da qual qualquer interessado pode participar, observadas às exceções previstas no art. 890 do Código de Processo Civil (Lei. 13.105, 2015) e outras legislações aplicáveis, havendo um conflito dos interessados em relação ao bem colocado em praça pública. Nos leilões judiciais, a venda depende de uma aprovação do juiz para a retirada do bem.

Por outro lado, o leilão extrajudicial não envolve processos judiciais e pode ter diferentes motivações. O leilão extrajudicial ocorre por iniciativa e autorização do proprietário do bem, chamado de comitente. Nesta modalidade não há o envolvimento ou a atuação do Poder Judiciário.

Para que o leilão extrajudicial ocorra, é necessário notificar o devedor do procedimento por meio de cartório de títulos e dar um prazo (contado a partir do recebimento da notificação extrajudicial) para que ele regularize o débito. Caso não haja o pagamento neste período concedido, a propriedade do bem passa a ser do credor, que poderá optar pela realização do leilão.

Caso no primeiro evento (primeira hasta) o maior lance oferecido seja inferior ao 
valor de avaliação do imóvel, será realizado um segundo leilão (segunda hasta), no qual será aceita a oferta que cubra a quantia da dívida somada às outras despesas.

Em caso de arrematação positiva, o leiloeiro expedirá o auto de arrematação, após o depósito do valor integral do lance vencedor. Caso não haja arrematação, o credor passa a dispor livremente da propriedade e poderá ficar com o imóvel ou vendê-lo da forma que desejar.

A arrematação é titulus acquirendi em favor do maior lance (agora arrematante ou adquirente), segundo a communis opinio no direito brasileiro. Deste modo, nem a entrega do ramo, nem a da carta de arrematação transferem para o arrematante o domínio da coisa arrematada, o qual só lhe pertence desde a posse (VELHO, 1885, p. 145).

De um lado, o leilão judicial é a penhora de bens para quitar o valor determinado em um processo judicial, no qual o patrimônio de um devedor é avaliado por um perito e levado a praça pública. Destarte, o leilão extrajudicial não é realizado pelo Poder Judiciário, mas pelo comitente credor da dívida. Nesses casos, a própria instituição retoma o bem por falta de pagamento e o leva a leilão.

\section{O ESTADO DA ARTE}

As constantes mudanças legislativas e a fixação de nova base de cálculo por decreto municipal servem de embasamento aos pedidos dos contribuintes nas ações judiciais em que se discute qual o montante de imposto que deve ser pago. Verificando o art. 35 do CTN (Lei no 5.172, 1966), as discussões judiciais estão norteadas em dois itens: se o valor venal do ITBI deve ser o mesmo do IPTU, sendo iguais as bases de cálculo e, consequentemente, o estabelecimento do valor venal de referência é ilegal; ou, segundo, se a base de cálculo do ITBI deve ser o valor declarado pelo contribuinte na operação de transmissão da propriedade.

Através de uma pesquisa doutrinária e jurisprudencial em livros e artigos científicos pertinentes ao tema, tendo natureza essencialmente teórica, centrada na análise doutrinária e, no que cabe, também legislativa do tema, verifica-se que a doutrina especializada no assunto e a jurisprudência compactuam a visão de que o valor venal deve corresponder ao valor da operação comercial de compra e venda. $\mathrm{O}$ valor venal, objetivando a correta incidência do ITBI, nada mais é que o valor pelo qual o bem seria transmitido em condições estáveis de mercado. 
Ora, com base nesta ideia e no art. 38 do CTN (Lei n $\left.{ }^{\circ} 5.172,1966\right)$, constata-se que a base de cálculo do imposto é o valor venal dos bens ou direitos transmitidos. Não é o preço de venda, mas o valor venal. A diferença entre preço e valor é importante. O preço é fixado pelas partes, que em princípio são livres para contratar. O valor dos bens é determinado pelas condições de mercado. Em princípio, pela lei da oferta e da procura (MACHADO, 2017, p. 395).

Nesta ocasião, a jurisprudência do Superior Tribunal de Justiça (STJ) objetiva julgar se é unívoco o conceito de valor venal, ou seja, se o valor venal estabelecido pelo município para o IPTU deve ser também aquele que servirá de base de cálculo do ITBI. Em diversas decisões, o STJ tem decidido reiteradamente que não é obrigatório que o valor venal utilizado para fins de apuração do IPTU seja igualmente atribuído ao imóvel objeto do negócio jurídico ensejador de pagamento de ITBI. Entretanto, salvo por voto proferido pelo Ministro Cesar Asfor Rocha no Recurso Especial no 1.219.229/SP (STJ - Resp: 1219229 SP 2010/0187600-1, Relator: Ministraro Mauro Campbell Marques, Data de julgamento: 07/11/2013, T2 - SEGUNDA TURMA, Data de publicação: Dje 03/02/2014. Disponível em www.stj.com.br. Acesso em 04 de fevereiro de 2021), não se verifica diretamente a legalidade da instituição do valor venal de referência.

Nesta lógica, o cerne do trabalho em questão defende que a base de cálculo do ITBI é o valor do imóvel apurado concretamente no negócio jurídico por meio do qual as partes se comprometeram a transmitir a propriedade sobre o bem imóvel, o que não acontece no IPTU, cuja base parte de plantas estabelecidas pela municipalidade. Com base neste entendimento, a Corte tem afirmado que o ITBI deve ser calculado sobre o valor efetivo da venda do bem, mesmo que este seja maior do que o valor venal adotado como base de cálculo para o lançamento do IPTU.

Sendo assim, o Estado da Arte obtido no presente texto concorda com a visão do STJ, que considera que o valor venal do imóvel é aquele que as partes do negócio jurídico acordaram mutuamente na transação e que foi declarado pelo contribuinte. Neste sentido, supõe-se que o preço efetivamente pago pelo adquirente do imóvel tende a refletir, com grande proximidade, seu valor venal, compreendido como o valor de uma venda regular, em condições normais de mercado.

Com sustentáculo no Estado da Arte defendido neste estudo, compreende-se que é o valor da arrematação (aquele valor cujo depósito serviu de causa a aquisição da propriedade) e não o valor da avaliação (ao valor que, segundo aferido em sede pericial ou 
por Oficial de Justiça avaliador, correspondendo ao valor médio de mercado do bem imóvel) o que reflete o "valor venal" do imóvel e, assim, deve ser adotado como base de cálculo. Ou seja, o preço alcançado em leilão e não o da avaliação reflete o valor venal do imóvel e deve ser utilizado como base de cálculo.

Este entendimento auxiliou na estrutução do presente trabalho e a verificar que no STJ há coerência nas decisões sobre o tema, já que é o valor da transação, como no caso do preço da arrematação, o que melhor representa, ou se aproxima do valor venal, entendido sempre como valor de mercado efetivamente praticado (em concreto) para viabilizar a transmissão da propriedade do bem.

Observa-se que o ITBI apresenta dificuldades práticas tanto para as administrações fazendárias quanto para os seus sujeitos passivos (contribuintes), tendo em vista que a escolha feita pelo CTN em determinar a base imponível por meio do valor de mercado do imóvel tem se revelado fonte de incertezas e litígio, sendo possível verificar que a expressão valor venal é suscetível de compreensões diversas.

Desta forma, é possível constatar que o valor venal do imóvel, no que se refere ao ITBI, admite ao menos três possíveis definições: primeiro, preço declarado pelas partes do imóvel; segundo, o valor venal atribuído ao imóvel para fins de IPTU; e, terceiro, o valor de mercado. Neste sentido, dentre as soluções apresentadas para a definição da base de cálculo do ITBI, a mais acertada é a apresentada pelo STJ (CORTEZ, 2020, p. 16).

Assim, concorda-se com a Corte Superior, que firmou o entendimento de que a base de cálculo é o valor da transação, conforme declarado pelo contribuinte, limitando-se à sistemática do lançamento por homologação, técnica que ademais de ser aquela prevista no CTN, também contribui para uma arrecadação consistente e objetiva deste imposto.

O STJ ponderou, por sua vez, que a Administração Pública, caso discorde do valor declarado pelo contribuinte, e respeitando o devido processo legal, pode arbitrar valor diverso, com fulcro no art. 148 do CTN (Lei no 5.172, 1966). Além disso, a posição do STJ respeita a necessária correlação que deve existir entre a base de cálculo de um imposto e seu fato gerador e, no caso, tem cabimento a desvinculação das bases de cálculo do IPTU, que incide sobre o direito de propriedade, e do ITBI que incide sobre a transmissão onerosa da propriedade.

Nesta lógica, defende-se que a base de cálculo do ITBI não deve necessariamente ser a mesma do IPTU porque embora em ambos os casos a previsão legal seja o valor venal do imóvel, são impostos com fatos geradores diferentes. Entretanto, é necessário verificar 
que os municípios enfrentam dificuldades práticas para fiscalizar os negócios jurídicos sobre os quais incide o ITBI, o que eventualmente resulta em evasão fiscal e posterior perda de arrecadação.

Não é por outra razão que a jurisprudência do STJ é pacífica ao admitir que, na hipótese de hasta pública, o preço da arrematação (e não o da avaliação) reflete o valor venal do imóvel e, deste modo, deve ser adotado como base de cálculo do ITBI, de acordo com seguintes julgados:

TRIBUTÁRIO. RECURSO ESPECIAL. AÇÃO DECLARATÓRIA. ITBI. ARREMATAÇÃO JUDICIAL. BASE DE CÁLCULO. VALOR DA ARREMATAÇÃO E NÃO O VENAL. PRECEDENTE. DISSÍDIO JURISPRUDENCIAL DEMONSTRADO. DIREITO LOCAL. SÚMULA 280 DO STF. OMISSÃO - ART. 535, CPC. INOCORRÊNCIA. RECURSO PROVIDO PELA ALÍNEA "C". 1. A arrematação representa a aquisição do bem alienado judicialmente, considerando-se como base de cálculo do ITBI aquele alcançado na hasta pública. (Precedentes: (...). 2. (...) Tendo em vista que a arrematação corresponde à aquisição do bem vendido judicialmente, é de se considerar como valor venal do imóvel aquele atingido em hasta pública. Este, portanto, é o que deve servir de base de cálculo do ITBI. (...) 7. Recurso especial parcialmente conhecido e provido (REsp 1188655/RS, Rel. Ministro LUIZ FUX, PRIMEIRA TURMA, julgado em 20/05/2010, DJe 08/06/2010. Disponível em www.stj.com.br. Acesso em 04 de fevereiro de 2021).

TRIBUTÁRIO. IMPOSTO DE TRANSMISSÃO INTER VIVOS. BASE DE CÁLCULO. VALOR VENAL DO BEM. VALOR DA AVALIAÇÃO

JUDICIAL. VALOR DA ARREMATAÇÃO. I - (...) Tendo em vista que a arrematação corresponde à aquisição do bem vendido judicialmente, é de se considerar como valor venal do imóvel aquele atingido em hasta pública. Este, portanto, é o que deve servir de base de cálculo do ITBI. II - Recurso especial provido (REsp 863.893/PR, Rel. Ministro FRANCISCO FALCÃO, PRIMEIRA TURMA, julgado em 17/10/2006, DJ 07/11/2006, p. 277. Disponível em www.stj.com.br. Acesso em 04 de fevereiro de 2021).

TRIBUTÁRIO. IMPOSTO DE TRANSMISSÃO DE BENS IMÓVEIS. BASE DE CÁLCULO. VALOR DA ARREMATAÇÃO. 1. O valor da arrematação é que deve servir de base de cálculo do Imposto de Transmissão de Bens Imóveis. Precedentes do STJ. 2. Recurso Especial provido. (REsp 1182640/RS, Rel. Ministro HERMAN BENJAMIN, SEGUNDA TURMA, julgado em 06/04/2010, DJe 20/04/2010. Disponível em www.stj.com.br. Acesso em 04 de fevereiro de 2021).

A fixação prévia e por presunção dos valores dos imóveis equivaleria ao uso de técnicas tributárias denominadas de pautas fiscais. A pauta fiscal consiste na prefixação de um valor para a obrigação tributária pela Administração Pública, tomado como teto, independente do efetivo e real valor da operação. A respeito do ITBI, a predefinição da base de cálculo poderia facilitar a fiscalização e arrecadação tributárias, uma vez que há uma grande dificuldade para a Administração em fiscalizar cada transação imobiliária para aferir 
se há ou não sonegação do imposto.

Ou seja, há que se encontrar um equilíbrio entre uma arrecadação tributária eficaz e o respeito aos direitos dos contribuintes. Atualmente, em que se exige que o contribuinte do ITBI ingresse em juízo para ter assegurado o direito de recolher o imposto sobre o valor da transação e não ter que se submeter ao valor venal de referência, ou ajuizar posteriormente a repetição do indébito, este equilíbrio mostra-se distante.

\title{
6. O EMBATE ENTRE OS MUNICÍPIOS E OS CONTRIBUINTES
}

As questões atinentes à base de cálculo do ITBI que, estando precisamente previstas no CTN como valor venal do imóvel de maneira evidente, tornaram-se objeto de diversas ações judiciais e controvérsias acerca de sua definição e quantificação. Este conflito centra-se principalmente na criação e utilização pelos municípios de uma base de cálculo auferida através de um valor de referência do imóvel objeto do negócio jurídico de transmissão onerosa.

Segundo Barreto (2009, p. 295):

\begin{abstract}
A base de cálculo do imposto é o valor venal dos bens ou direitos transmitidos ou cedidos. O valor venal não é necessariamente o valor do negócio realizado. A Constituição e o Código tributário Nacional não exigem que o valor venal coincida com o valor da efetiva transação imobiliária, onde até os fatores subjetivos poderiam interferir na sua fixação. (...). Não se olvide que valor venal é o preço provável que o imóvel alcançará para compra e venda à vista, diante de mercado estável e quando comprador e vendedor têm plena consciência do potencial de uso e ocupação que ao imóvel pode ser dado. Não se esqueça que o valor venal é mensuração extremamente difícil, porque influenciada por uma série de fatores internos e externos, de natureza subjetiva, o que impede que seja transformada em número inconteste.
\end{abstract}

O ITBI está sujeito a lançamento por homologação, ou declaração, de modo que cabe ao contribuinte declarar o valor da transação e efetivar o recolhimento da quantia correspondente. Assim, não há intervenção do Fisco no momento da apuração do imposto, de acordo com o art. 150 do CTN (Lei n ${ }^{\circ}$ 5.172, 1966). O município pode homologar ou não o lançamento apurado pelo contribuinte.

$\mathrm{Na}$ arrematação, considera-se como base de cálculo do ITBI aquele alcançado no leilão público. O entendimento é da Primeira Turma do Superior Tribunal de Justiça (STJ), ao julgar o recurso interposto por uma cidadã contra decisão do Tribunal de Justiça do Rio Grande do Sul (TJRS).

Observa-se que a jurisprudência do STJ é unânime ao afirmar que, em situação de 
hasta pública, o preço de arrematação (e não o da avaliação) reflete o valor venal do imóvel e, assim, deve ser adotado como base de cálculo do ITBI.

Nesta ocasião, o relator do recurso acima, ministro Luiz Fux (STJ - Resp: 1188655/RS 2010/0061696-9, Relator: Ministro LUIZ FUX, Data do julgamento: 20/05/2010, T1 - PRIMEIRA TURMA, Data de publicação: Dje 08/06/2010. Disponível em www.stj.com.br. Acesso em 04 de fevereiro de 2021), enfatizou o entendimento, já firmado pela Corte, de que a base de cálculo do ITBI deve ser a do valor alcançado em leilão. Uma vez que a arrematação corresponde à aquisição do bem vendido judicialmente, é de se considerar como valor venal do imóvel aquele atingido em hasta pública.

De modo geral, os municípios, dentro de sua competência, apontam que a base de cálculo é o valor venal do bem, este compreendido como o valor de referência de negociação em condições normais de mercado.

Os entes públicos, de modo geral, ignoram o valor da transação declarado pelo contribuinte, presumindo má-fé e falsidade por parte deste, e exigem o recolhimento do imposto sobre valor por eles determinado, sem procedimento administrativo prévio, fazendo uso de uma avaliação discricionária e unilateral, feita sem qualquer vistoria precisa e detalhada do imóvel.

Com efeito, se o valor apresentado pelo contribuinte no lançamento do ITBI (por declaração ou por homologação) não merece fé, o ente público igualmente pode questionálo e arbitrá-lo, no decorrer de regular procedimento administrativo, segundo o art. 148 do CTN (Lei n ${ }^{\circ}$ 5.172, 1966).

Caso não haja valor declarado ou o valor não merecer fé-pública, o município pode arbitrar o valor, desde que instaure o devido e regular processo administrativo. A jurisprudência já se manifestou quanto à necessidade de o município obedecer às regras para alterar a base de cálculo do ITBI, sendo ilegal seu arbitramento unilateral:

Mandado de Segurança. ITBI. Base de cálculo. Sentença que concedeu a segurança para determinar que a base de cálculo do ITBI corresponda ao valor da transação. Pretensão à reforma. Desacolhimento. Base de cálculo. Valor venal do imóvel no momento da compra e venda. Importância que pode ser diversa daquela utilizada para fins de IPTU. Normas locais que conferem ao Executivo a estimativa prévia do valor venal. Ofensa ao princípio da legalidade e inobservância do art. 148 do CTN. Inconstitucionalidade dos artigos $7^{\circ}$ - A e $7^{\circ}-B$ da Lei Municipal n. ${ }^{\circ} 11.154 / 1991$, que permitem a estimativa prévia e unilateral do valor e invertem a ordem do artigo 148 do CTN, reconhecida pelo Órgão Especial do TJSP na Arguição de Inconstitucionalidade n. 005669319.2014.8.26.0000. Manutenção do art. $7^{\circ}$ da mesma Lei Municipal n. ${ }^{\circ}$ $11.154 / 1991$, que estabelece como valor venal aquele pelo qual o bem ou direito 
seria negociado à vista, em condições normais de mercado. Reexame obrigatório provido em parte e recurso voluntário ao qual se nega provimento. Apelação com revisão n. 1011880-85.2015.8.26.0053. ACORDAM, em 18 Câmara

de Direito Público do Tribunal de Justiça de São Paulo, proferir a seguinte decisão: "Deram provimento em parte ao recurso oficial e negaram provimento ao recurso voluntário V. U.", de conformidade com o voto do Relator, que integra este acórdão. O julgamento teve a participação dos Exmos. Desembargadores BEATRIZ BRAGA (Presidente sem voto), WANDERLEY JOSÉ FEDERIGHI E BURZA NETO. São Paulo, 15 de dezembro de 2016 Relator: Des. RICARDO CHIMENTI (TJ-SP - APL: 10228613720198260053/SP, Relator: Ricardo Chimenti, Data de julgamento: 16/04/2020, $18^{\text {a }}$ Câmara de Direito Público, Data de publicação: 16/04/2020. Disponível em www.stj.com.br. Acesso em 04 de fevereiro de 2021).

É clara a discricionariedade e subjetividade do Fisco, que só atende ao texto legal, que exige a cobrança do imposto sobre o valor da transação, quando lhe favorece e implica em aumento na arrecadação. Na prática, são raras as situações nas quais o recolhimento do ITBI é feito pelo valor da transação, uma vez que os municípios, de maneira geral, fixam os valores venais para fins de ITBI em nível acima aos valores praticados pelo mercado (OSÓRIO, 2021, p. 1).

Nesta lógica, no que se refere ao ITBI, cabe ao próprio contribuinte declarar a base de cálculo e antecipar o recolhimento do imposto, cabendo ao Fisco estudar a operação, aprovando-a ou não. Determinados tribunais têm viabilizado ao contribuinte o recolhimento do imposto sobre o valor da transação, assim como permitido a restituição do valor pago em excesso.

Segundo o CTN, a base é o valor venal, este apurado segundo critérios objetivos. Todavia, é possível utilizar o valor da transação, aplicando-se o disposto no art. 148 do CTN em caso de divergência apresentada pelo Fisco (MACHADO, 2017, p. 409).

Ao município foi atribuida a competência para legislar sobre ITBI (BRASIL, 1988). Contudo, conhecendo-se a grande importância do mercado imobiliário para a economia brasileira, é relevante garantir aos cidadãos uma tributação estável e coerente nos negócios jurídicos.

\section{CONSIDERAÇÕES FINAIS}

A base de cálculo do ITBI é o valor venal do bem ou direitos transmitidos. Em certas repartições públicas municipais, a base de cálculo adotada não faz referência ao valor venal, mas sim o valor assinalado pelo ente público. Nesta lógica, observa-se a existência do valor venal para cobrança de IPTU; valor venal para fins de ITBI e do valor real de 
mercado do bem.

Nesta ocasião, o valor venal para cobrança de IPTU e o valor venal pra fins de incidência do ITBI são determinados pelo município. Porém, importante salientar que o valor venal de referência para fins de ITBI já foi, várias vezes, decidido como ilegal pela jurisprudência nacional, por se tratar de uma aplicação singular do ente público com fins arrecadatórios.

A maneira como se apura a base de cálculo e a forma de lançamento do IPTU e do ITBI são distintas, razão pela qual não se justifica a ligação entre os valores desses tributos. O Código Tributário não estipula que a base de cálculo do ITBI seja aquela utilizada para a correta mensuração do IPTU, mas sim que a base de cálculo do ITBI seja o valor venal dos bens ou direitos transmitidos.

O valor venal, para fins de arrecadação do ITBI, faz alusão ao valor pelo qual o bem seria transmitido em condições regulares de mercado. Nesta lógica, a legislação, a doutrina atuante no tema e a jurisprudência apontam no sentido de que o valor venal deve fazer alusão ao valor do negócio jurídico entabulado.

Em imóveis obtidos por meio de leilões judiciais e extrajudiciais, como o valor de aquisição demonstra o efetivo valor de mercado do imóvel, o ITBI deve ser obrigatoriamente recolhido sobre o valor de arrematação. Vários municípios, todavia, exigem o ITBI sobre bases distintas do valor do arremate.

Por fim, apesar de o Código Tributário Nacional estabelecer que a base de cálculo do ITBI é o valor venal dos bens, ao tratar da aquisição de bens levados em praça pública, consolidou-se o entendimento que o tributo em questão incide sobre o valor de arrematação.

\section{REFERÊNCIAS}

BARRETO, Aires Fernandino. Curso de Direito Tributário Municipal. São Paulo: Editora Saraiva, 2009.

BRASIL. Constituição (1988). Constituição da República Federativa do Brasil. Brasília: Senado Federal, 1988. Disponível em www.planalto.gov.br. Acesso em 03 de fevereiro de 2021.

BRASIL. Lei $\mathrm{n}^{\circ}$ 8.666, de 21 de junho de 1993. Regulamenta o art. 37, inciso XXI, da 
Constituição Federal, institui normas para licitações e contratos da Administração Pública e dá outras providências. Diário Oficial da União, Brasília, DF, 22 jun. 1993. Disponível em: http://www.planalto.gov.br. Acesso em: 02 de fevereiro de 2021.

CARVALHO, Paulo de Barro. Derivação e positivação no direito tributário. São Paulo: Noeses, 2013.

COÊLHO, Sacha Calmon Navarro. Curso de Direito Tributário Brasileiro. 2. ed. Rio de Janeiro: Forense, 2015.

CORTEZ, Maria Eugênia Chiampi. A controvérsia sobre a base de cálculo do imposto sobre a transmissão de bens imóveis itbi no município de são Paulo. Disponível em: https://migalhas.uol.com.br/arquivos/2019/4/art20190411-05.pdf. Acesso em 15 de outubro de 2020.

HARADA, Kiyoshi. Imposto sobre transmissão de bens imóveis (ITBI). Jus Navigandi, Teresina, ano 5, n. 40, 1 mar. 2000. Disponível em: http://jus.com.br. Acesso em: 23 de novembro de 2020.

HARADA, Kiyoshi. ITBI na arrematação de bem imóvel em hasta pública. Genjurídico.com.br, 2019. Disponível em: http://genjuridico.com.br. Acesso em: 02 de fevereiro de 2021.

Lei $n^{\circ} 5.172$, de 25 de outubro de 1966. Institui o Código Tributário Nacional. Diário Oficial da República Federativa do Brasil, Brasília, DF, 27 de outubro de 1966. Disponível em: www.planalto.gov.br. Acesso em 02 de fevereiro de 2021.

Lei $\mathrm{n}^{\circ}$ 13.105, de 16 de março de 2015. Institui o Código de Processo Civil. Diário Oficial da União, Brasília, DF, 17 março de 2015. Disponível em https://www.planalto.gov.br. Acesso em 02 de fevereiro de 2021.

MACHADO, Hugo de Brito. Curso de Direito Tributário. 38. ed. São Paulo, Malheiros, 2017.

OSÓRIO, Ana Carolina. Cobrança do itbi tem várias ilegalidades. Disponível em https://www.conjur.com.br. Acesso em 02 de fevereiro de 2021. 
PASSOS, Josué Modesto. Arrematação no registro de imóveis: continuidade do registro e natureza da aquisição. 2. ed. São Paulo: Editora Revista dos Tribunais, 2015.

REsp 863.893/PR, Rel. Ministro FRANCISCO FALCÃO, PRIMEIRA TURMA, julgado em 17/10/2006, DJ 07/11/2006. Disponível em www.stj.com.br. Acesso em 04 de fevereiro de 2021.

REsp 1182640/RS, Rel. Ministro HERMAN BENJAMIN, SEGUNDA TURMA, julgado em 06/04/2010, DJe 20/04/2010. Disponível em www.stj.com.br. Acesso em 04 de fevereiro de 2021.

REsp 1188655/RS, Rel. Ministro LUIZ FUX, PRIMEIRA TURMA, julgado em 20/05/2010, DJe 08/06/2010. Disponível em www.stj.com.br. Acesso em 04 de fevereiro de 2021.

STJ - Resp: 1219229 SP 2010/0187600-1, Relator: Ministraro Mauro Campbell Marques, Data de julgamento: 07/11/2013, T2 - SEGUNDA TURMA, Data de publicação: Dje 03/02/2014. Disponível em www.stj.com.br. Acesso em 04 de fevereiro de 2021.

TJ-SP - APL: 10228613720198260053/SP, Relator: Ricardo Chimenti, Data de julgamento: 16/04/2020, 18a Câmara de Direito Público, Data de publicação: 16/04/2020. Disponível em www.stj.com.br. Acesso em 04 de fevereiro de 2021.

VELHO, Bernardo Teixeira de Moraes Leite. Monografia jurídica e prática das execuções de sentenças em processo civil. Rio de Janeiro: A. Guimarães, 1885. 